Supporting Information

\title{
Facile Way to Prepare a Porous Molecular Imprinting Lock for Specifically Recognizing Oxytetracyclin Based on Coordination
}

Yi Zhang, Yang Xie, Haizhu Shi, Zhaoju Wu, Chungu Zhang, Shun Feng*

School of Life Science and Engineering, Southwest Jiaotong University, Chengdu 610031, China

* Corresponding author: Tel: +86 028 87634296. Email: fengshunxd@ hotmail.com.

\section{Table of Contents}

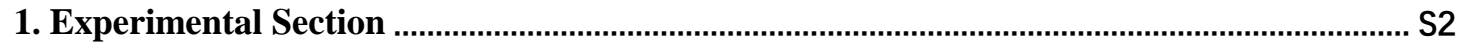

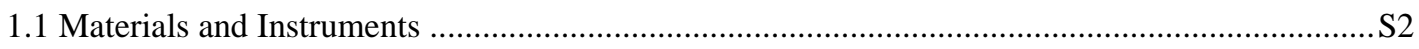

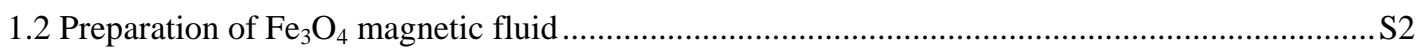

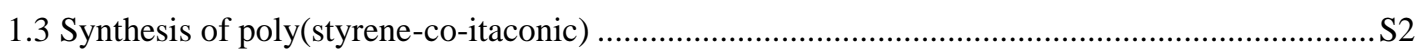

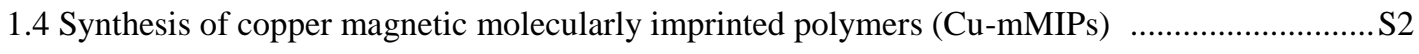

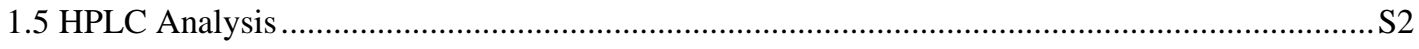

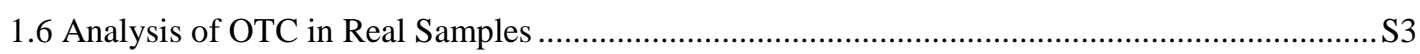

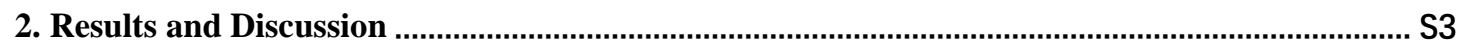

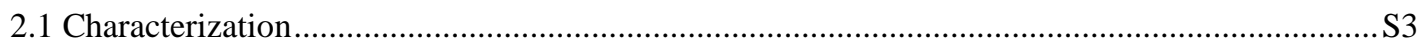

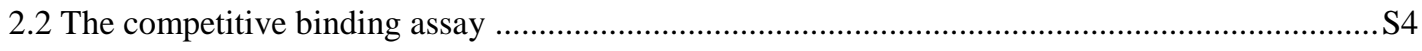

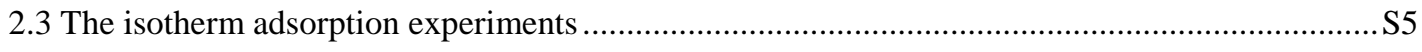

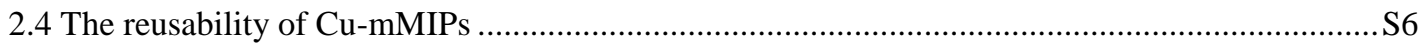

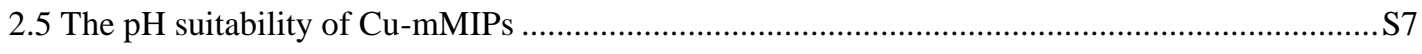

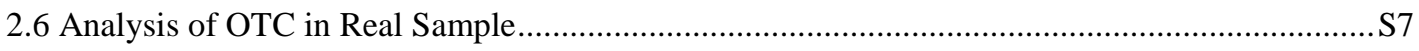

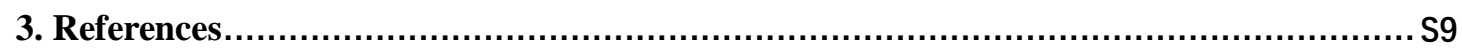

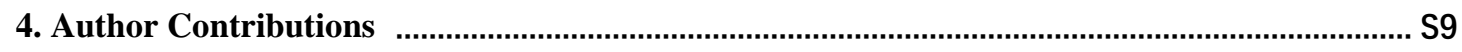




\section{Experimental Section}

\subsection{Materials and Instruments}

Reagents and Solutions Ammonium ferrous sulfate $\left(\left(\mathrm{NH}_{4}\right)_{2} \mathrm{Fe}\left(\mathrm{SO}_{4}\right)_{2} \cdot 6 \mathrm{H}_{2} \mathrm{O}\right)$, 2,2-azodiisobutyronitrile (AIBN), sodium hydroxide $(\mathrm{NaOH})$, sodium chloride $(\mathrm{NaCl})$, oleic acid, copper(II) sulfate pentahydrate $\left(\mathrm{CuSO}_{4} \cdot 5 \mathrm{H}_{2} \mathrm{O}\right)$, oxalic acid and trifluoroacetic acid were analytical grade and purchased from Adamas Reagent Co., Ltd. (Shanghai, China). Styrene (St), itaconic acid (ITA), oxytetracycline (OTC), amoxicillin, sulfadiazine, chloramphenicol, dimetridazole and tetracycline were obtained from Aladdin Industrial Corporation (Shanghai, China) or, High-performance liquid chromatography (HPLC) solvents were purchased from Fisher Scientific (US). Ultra-pure water $\left(18.2 \mathrm{M} \Omega \mathrm{cm}^{-1}\right)$ was obtained with a KL-UP-II water system (Tangshi Kangning Technology Development Co., Ltd., Chengdu, China) and used thoroughly in experiments. AIBN was purified by recrystallization, St was purified by removed the inhibitor and reduced pressure distillation. Other reagents were analytically pure and used without further pretreatment.

\subsection{Preparation of $\mathrm{Fe}_{3} \mathrm{O}_{4}$ Magnetic Fluid}

The magnetic fluid was synthesized as our previous work. ${ }^{1}$ In short, $30 \mathrm{~mL} 0.1 \mathrm{~g} / \mathrm{mL} \mathrm{NaOH/ethanol/oleic}$ acid $(1: 1: 1, \mathrm{v} / \mathrm{v} / \mathrm{v})$ solution and $10 \mathrm{~mL} 0.2 \mathrm{~mol} / \mathrm{L}\left(\mathrm{NH}_{4}\right)_{2} \mathrm{Fe}\left(\mathrm{SO}_{4}\right)_{2} \cdot 6 \mathrm{H}_{2} \mathrm{O} a q$ were mixed under vigorous stirred at room temperature. Adn then the mixture was transferred into a $100 \mathrm{~mL}$ Teflon stainless steel autoclave and heated at $180^{\circ} \mathrm{C}$ for $10 \mathrm{~h}$. After naturally cooled to room temperature, the precipitate was removed out and washed with $10 \mathrm{~mL}$ cyclohexane and $30 \mathrm{~mL}$ ethanol triplicates, separatly. Finally, the resulted black product was suspended in $4 \mathrm{~mL}$ chloroform and stored before use.

\subsection{Synthesis of Poly(styrene-co-itaconic)}

In brief, $5.2 \mathrm{~mL}$ St and $80 \mathrm{mg}$ AIBN were added into $30 \mathrm{~mL}$ methanol, $1.3 \mathrm{~g}$ Ita was dissolved in $10 \mathrm{ml}$ water. Then transferred into a $100 \mathrm{~mL}$ teflon stainless steel autoclave and heated at $100^{\circ} \mathrm{C}$ for $10 \mathrm{~h}$. After cooled to room temperature naturally, then the resulted milky colloidal precipitate was washed with $50 \mathrm{~mL}$ ethanol triplicates, and dried at $35^{\circ} \mathrm{C}$ for $10 \mathrm{~h}$.

\subsection{Synthesis of Copper Magnetic Molecularly Imprinted Polymers (Cu-mMIPs)}

In a $100 \mathrm{~mL}$ pear-shaped flask, $0.867 \mathrm{~g}$ of poly(styrene-co-itaconic) and $800 \mu \mathrm{L}$ magnetic fluid solution were dissolved in $8 \mathrm{~mL}$ of chloroform. And then $50 \mathrm{~mL}$ aquous solution containing $0.500 \mathrm{~g}$ oxytetracycline (OTC), $1.000 \mathrm{~g} \mathrm{CuSO}_{4} \cdot 5 \mathrm{H}_{2} \mathrm{O}$ and $0.293 \mathrm{~g} \mathrm{NaCl}$ was added into the flask. The mixture was stirring at 300 $\mathrm{rpm}$ at ambient temperature. Two hours later, it was rather stirring at $70^{\circ} \mathrm{C}$ for $1 \mathrm{~h}$ and cooled to room temperature. The resulted product was separated with assistance of an external magnet. Subsequently, it was washed out with ultra-pure water, ethanol and $10 \%$ ammonia solution sequentially. After that, the product was added into $50 \mathrm{ml}$ of $0.2 \mathrm{~mol} / \mathrm{L} \mathrm{CuSO}_{4} \cdot 5 \mathrm{H}_{2} \mathrm{O}$. After being shaken $30 \mathrm{~min}$, the particles was washed three times with deionized water and dried at $35^{\circ} \mathrm{C}$. The resulted particle was denoted as $\mathrm{Cu}$-mMIPs.

In parallel, one magnetic molecularly imprinted polymers towards OTC (denoted as c-mMIPs) was prepared with oil-in-water emulsifier-free emulsion technology under identical conditions as that for $\mathrm{Cu}$-mMIPs except no $\mathrm{Cu}$ (II) added in the reaction system. And one magnetic non-imprinted polymers (mNIPs) was prepared using same method except no OTC added.

\subsection{HPLC Analysis}

The analyses of sample were performed on a Waters 1525 HPLC system with photodiode array detector. All separations were achieved on a Waters Symmery® $C_{18}$ column $(4.6 \mathrm{~mm} \times 150 \mathrm{~mm}, 5 \mu \mathrm{m})$. The 
conditions were listed as follows: flow rate $1.0 \mathrm{~mL} / \mathrm{min}$, injecting volume $10 \mu \mathrm{L}$, and column temperature $30^{\circ} \mathrm{C}$. The mobile phase consisted of $(\mathrm{A})$ acetonitrile-methanol $(1: 1, \mathrm{v} / \mathrm{v})$ and $(\mathrm{B}) 0.01 \mathrm{~mol} / \mathrm{L}$ sodium dihydrogen phosphate $(\mathrm{pH} 3)$. Gradient elution was used. In competitive binding assay, the gradient elution started with $16 \% \mathrm{~A}$, linearly increased to $20 \% \mathrm{~A}$ in $10.0 \mathrm{~min}$ and further linearly increased to $30 \% \mathrm{~A}$ in 10.0 to $30.0 \mathrm{~min}$, then linearly decreased to $40 \% \mathrm{~A}$ in 30.0 to $35.0 \mathrm{~min}$ and further linearly decreased to $16 \% \mathrm{~A}$ in 35.0 to $40.0 \mathrm{~min}$ with a total running time of $40 \mathrm{~min}$. The detection wavelength as same as descripted of selectivity test. And for analyzing real samples, isocratic elution was used with $18 \% \mathrm{~A}$ as the mobile phase, a total running time $10 \mathrm{~min}$ and the detection wavelength $354 \mathrm{~nm}$. The quantification was based on the peak area with standard curve method.

\subsection{Analysis of OTC in Real Samples}

The pork liver was brought from a local market. An amount of $10.0 \mathrm{~g}$ of pork liver was homogenized with $3 \mathrm{~mL}$ of $0.01 \mathrm{~mol} / \mathrm{L}$ EDTA buffer firstly. And then $40 \mathrm{~mL}$ acetonitrile, $3.0 \mathrm{~mL} 0.01 \mathrm{~mol} / \mathrm{L} \mathrm{CuSO}_{4} \cdot 5 \mathrm{H}_{2} \mathrm{O}$ and $5.0 \mathrm{~mL} 0.01 \mathrm{~mol} / \mathrm{L}$ trifluoroacetic acid were added. After ultrasonic extraction for $10 \mathrm{~min}$, the homogenate was centrifuged at $20000 \mathrm{~g}$ for $10 \mathrm{~min}$. The supernatant was collected and dried. Subsequently, it was dissolved in $9 \mathrm{~mL}$ of water. Afterwards OTC was spiked in the solution to $0.1,0.3$, or $1.0 \mu \mathrm{g} / \mathrm{mL}$. Then 10 mg Cu-mMIPs was dispersed in the solution. After incubated for $1 \mathrm{~h}$, the particles was removed out and washed with $2 \mathrm{~mL}$ water two times. Finally, $1 \mathrm{~mL} 2.5 \mathrm{mmol} / \mathrm{L}$ oxalic acid was used to elute the captured OTA for two times. The eluting fractions were combined and analyzed directly with HPLC. All experiments were performed in triplicates.

\section{Results and Discussion}

\subsection{Characterization}

The average size of $\mathrm{Fe}_{3} \mathrm{O}_{4}$ about is determined by a dynamic light scatter (DLS, Nano-Zen 3600, Malvern, UK). As shown in Figure S1, it is about $15 \mathrm{~nm}$ with a polydispersity index (PDI) of 0.063. Such a small particle size and good dispersion of $\mathrm{Fe}_{3} \mathrm{O}_{4}$ make it easy to be doped into MIPs and without occupied too much space of MIPs, which has little impact on the number of binding sites.

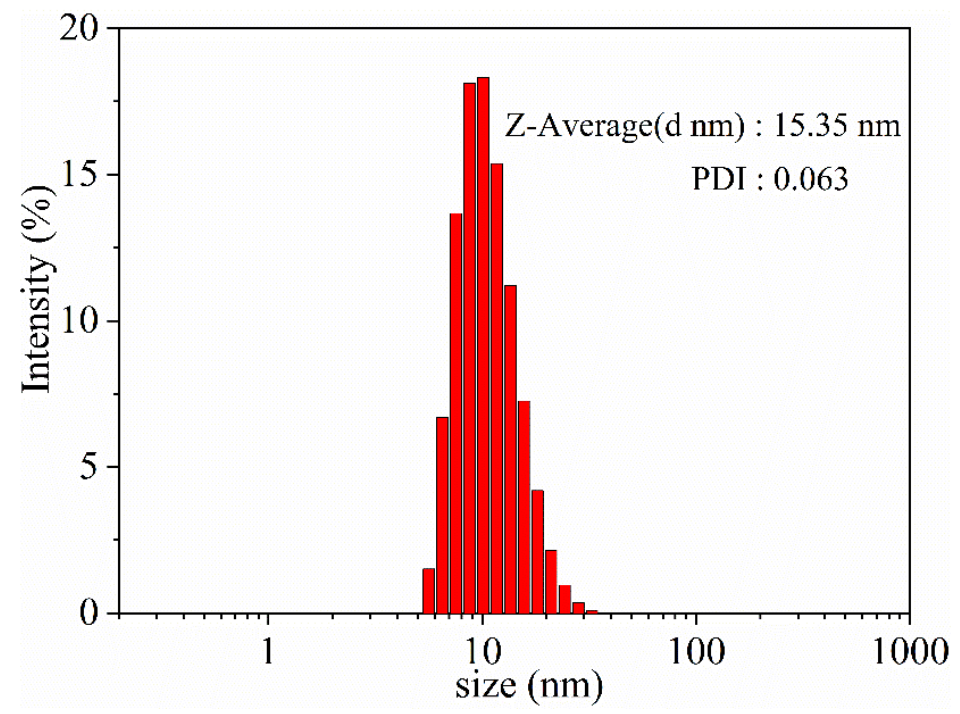

Figure S1. Particle size distribution of $\mathrm{Fe}_{3} \mathrm{O}_{4}$. 
Fourier transform infrared spectra were recorded on a FT-IR spectrophotometer (Nicolet 6700, Thermo Fisher, USA). In Figure S2, the band at $612 \mathrm{~cm}^{-1}$ is the characteristic absorption of $\mathrm{Fe}_{3} \mathrm{O}_{4}$, the peaks at 3026 $\mathrm{cm}^{-1}$ and $756 \mathrm{~cm}^{-1}$ were attributed to the stretching vibrations and bending vibration of $\mathrm{Ar}-\mathrm{H}$ on styrene, and the feature peak at $1705 \mathrm{~cm}^{-1}$ resulted from $\mathrm{C}=\mathrm{O}$ group of ITA, $\mathrm{Cu}-\mathrm{mMIPs}$ and poly(ITA-co-St) spectra, as marked in corresponding FT-IR curves. It indicated the preparation of $\mathrm{Cu}$-mMIPs successfully.

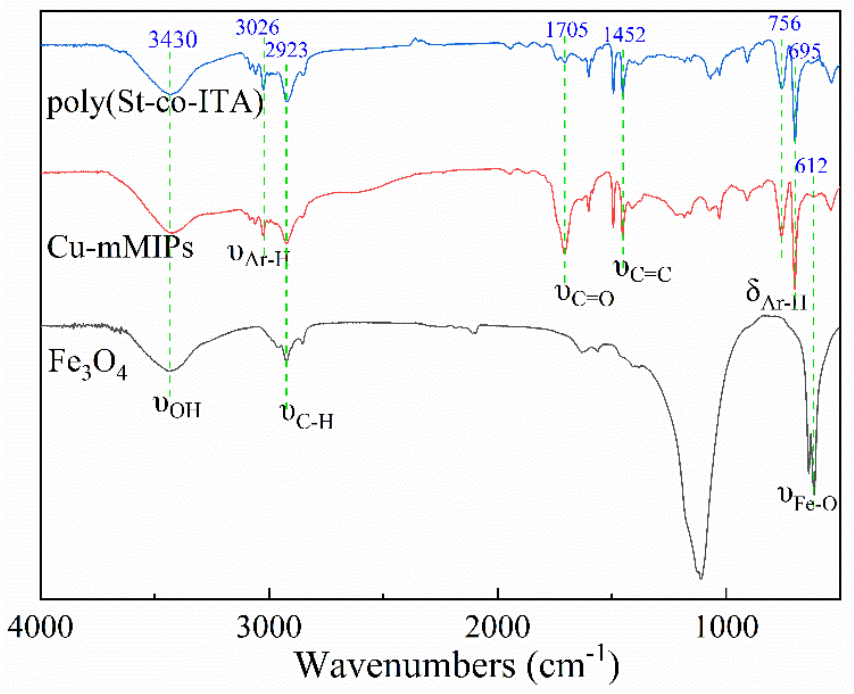

Figure S2. The FT-IR spectra of $\mathrm{Fe}_{3} \mathrm{O}_{4}, \mathrm{Cu}$-mMIPs and poly(St-co-ITA).

\subsection{The Competitive Binding Assay}

The competitive was investigated by dispersing $10 \mathrm{mg} \mathrm{Cu}$-mMIPs in $10 \mathrm{~mL}$ mixture of above six drugs (each is $30 \mu \mathrm{g} / \mathrm{mL}$ ) for $1 \mathrm{~h}$ under shaken. And the components in the supernatant were determined by HPLC. And the results are summarized in Figure S3. As shown, adsorption capacities for TC and OTC on $\mathrm{Cu}$-mMIPs are far higher than those on mNIPs. While there are few differences for amoxicillin, sulfadiazine, chloramphenicol and dimetridazole. It reveals the high specificity of $\mathrm{Cu}$-mMIPs towards OTC and its structure analog TC.

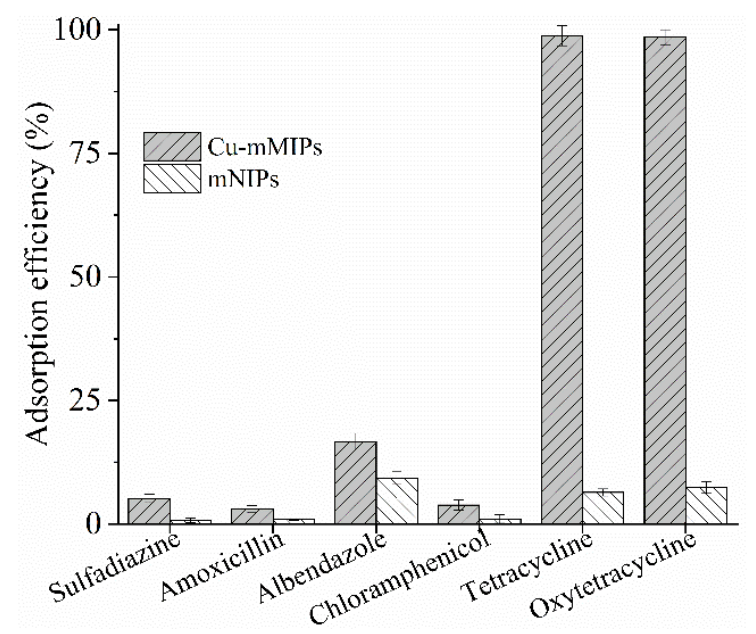

Figure S3. Competitive binding assay of $\mathrm{Cu}$-mMIPs and mNIPs towards different drugs. 


\subsection{The Isotherm Adsorption Experiments}

In the isotherm adsorption experiments, $10 \mathrm{mg} \mathrm{Cu}$-mMIPs, c-mMIPs or mNIPs was dispersed in $10.0 \mathrm{~mL}$ standard OTC $a q$ was added with concentrations varied from $0.3-100 \mu \mathrm{g} / \mathrm{mL}$, separately. After shaken for 1 $\mathrm{h}$, the particles was removed out with assistance of an external magnet. The concentration of residual OTC in the solution was measured with UV-Vis at $354 \mathrm{~nm}$ according to the standard curve method.

After data analyses, it can be found from Figure S4, there is only one straight line for mNIPs. The linear regression equation is $\mathrm{y}=-9.748 \times 10^{-2} \mathrm{x}+0.208(\mathrm{R}=0.927)$, and the $\mathrm{k}_{\mathrm{d}}$ and $\mathrm{Q}_{\max }$ values are $10.259 \mu \mathrm{g} / \mathrm{mL}$ and $2.134 \mathrm{mg} / \mathrm{g}$, respectively. Above results indicate only one type of adsorption existing, an inevitable non-specific adsorption for mNIPs towards OTC. For c-mMIPs there are two types of adsorption, specific and nonspecific adsorption existing towards OTC. The linear regression equations for two curves are $\mathrm{y}=$ $-0.564 x+1.008(R=0.992)$ and $y=-4.759 \times 10^{-2} x+0.316(R=0.964)$, respectively. And the corresponding $\mathrm{k}_{\mathrm{d}}$ and $\mathrm{Q}_{\max }$ values are $21.013 \mu \mathrm{g} / \mathrm{mL}$ and $6.640 \mathrm{mg} / \mathrm{g}$ for the high affinity sites, $1.773 \mathrm{mg} / \mathrm{L}$ and $1.787 \mathrm{mg} / \mathrm{g}$ for the low affinity sites, respectively. As comparison, for $\mathrm{Cu}-\mathrm{mMIPs}$, it is also only one fitted curve. The linear regression equation is $y=-1.608 \times 10^{-2} \mathrm{x}+1.006(\mathrm{R}=0.953)$, the $\mathrm{k}_{\mathrm{d}}$ and $\mathrm{Q}_{\max }$ values are $62.189 \mu \mathrm{g} / \mathrm{mL}$ and $62.567 \mathrm{mg} / \mathrm{g}$. It means that the amount of nonspecific adsorption is too small to be covered by the specific adsorption. The results of isotherm adsorption experiments rather testify the excellent performance of Cu-mMIPs towards OTC.
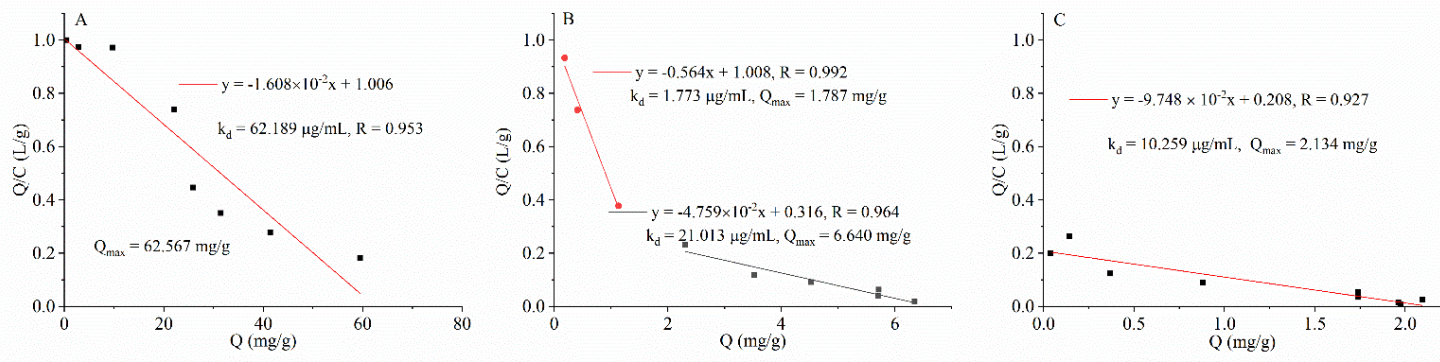

Figure S4. The Scatchard curves of (A) Cu-mMIPs, (B) c-mMIPs, (C) mNIPs.

The adsorption kinetic mechanism was further analyzed, from the above kinetic using pseudo-first-order (Eq. 1) and pseudo-second order (Eq. 2) rate equation expressed as follows: ${ }^{2}$

$$
\begin{aligned}
& \ln \left(Q_{e}-Q_{t}\right)=\ln Q_{e}-k_{1} t \\
& \frac{t}{Q_{t}}=\frac{1}{k_{2} Q_{e}^{2}}+\frac{t}{Q_{e}}
\end{aligned}
$$

Where $Q_{e}$ and $Q_{t}(\mathrm{mg} / \mathrm{g})$ are the amount of OTC adsorbed onto adsorbents at the equilibrium and time $t$ $(\mathrm{min})$, respectively. $\mathrm{k}_{1}(1 / \mathrm{min})$ value is the rate constant of pseudo- first -order adsorption, and $\mathrm{k}_{2}$ $(\mathrm{g} /(\mathrm{mg} \cdot \mathrm{min}))$ value is the rate constant of pseudo- second -order adsorption. As shown in Figure S5, the pseudo-second-order model fits the experimental data quite well deducing from the relatively high regression coefficients $\left(\mathrm{R}^{2}>0.99\right)$, indicating that the adsorption processes on these materials are controlled by chemical adsorption rather than diffusion adsorption. By comparing the slope and the intercept of liner regression equations in Figure S6B, it could be concluded that adsorption processes of OTC on the $\mathrm{Cu}$-mMIPs is much faster than that on the mNIPs, which should be attributed to the nature of the coordination. 

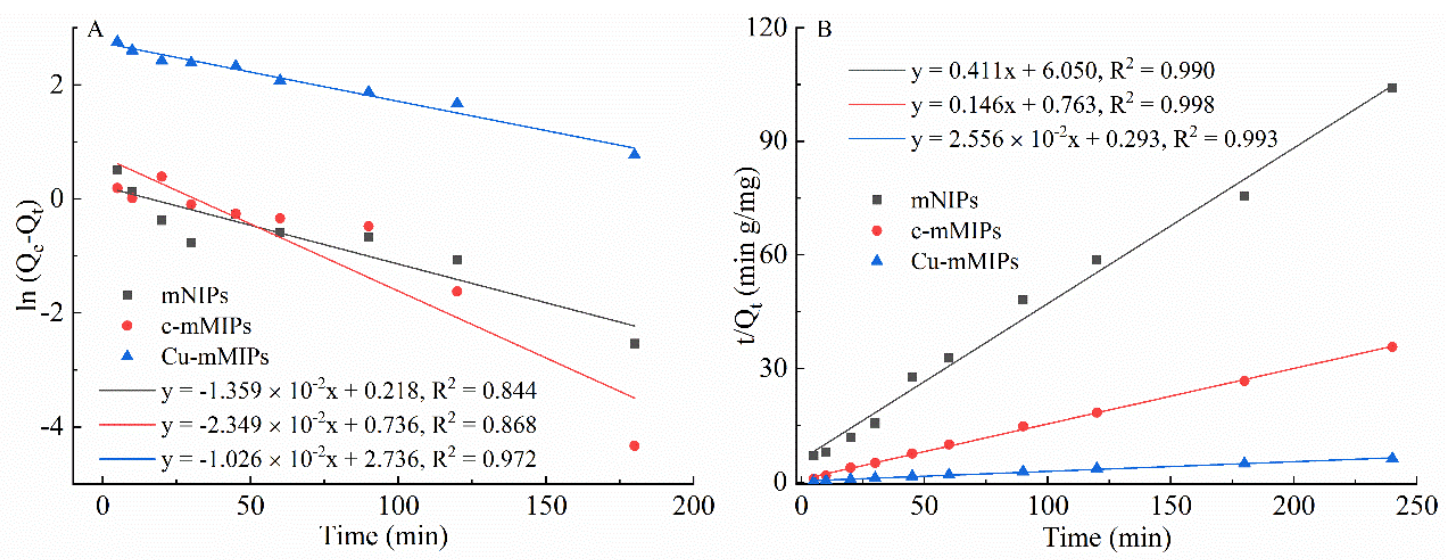

Figure S5. (A) The pseudo-first-order, (B) pseudo-second-order kinetic models of mNIPs, c-mMIPs, and Cu-mMIPs.

Table S1 The results of kinetics absorption experiment of $\mathrm{Cu}-\mathrm{mMIPs}, \mathrm{c}-\mathrm{mMIPs}$ and mNIPs.

\begin{tabular}{|c|c|c|c|c|c|}
\hline & Kinetic model & Linear regression equation & $\mathrm{K}(\mathrm{g} /(\mathrm{mg} \cdot \mathrm{min})$ & Qe $(\mathrm{mg} / \mathrm{g})$ & $\mathrm{R}^{2}$ \\
\hline \multirow[t]{2}{*}{ Cu-mMIPs } & Pseudo-first-order & $y=-1.359 \times 10^{-2} x+0.218$ & $1.359 \times 10^{-2}$ & 1.244 & 0.844 \\
\hline & Pseudo-second-order & $y=2.556 \times 10^{-2} x+0.293$ & $2.230 \times 10^{-3}$ & 39.124 & 0.993 \\
\hline \multirow[t]{2}{*}{ c-mMIPs } & Pseudo-first-order & $y=-2.349 \times 10^{-2} x+0.736$ & $2.349 \times 10^{-2}$ & 2.088 & 0.868 \\
\hline & Pseudo-second-order & $y=0.146 x+0.763$ & $2.794 \times 10^{-2}$ & 6.849 & 0.998 \\
\hline \multirow[t]{2}{*}{ mNIPs } & Pseudo-first-order & $y=-1.026 \times 10^{-2} x+2.736$ & $1.026 \times 10^{-2}$ & 15.430 & 0.972 \\
\hline & Pseudo-second-order & $y=0.411 x+6.050$ & $2.792 \times 10^{-2}$ & 2.433 & 0.990 \\
\hline
\end{tabular}

\subsection{The Reusability of Cu-mMIPs}

To investigate the reusability, $10 \mathrm{mg}$ Cu-mMIPs was continuously used to absorb OTC in standard solution. The procedure was as same as that in the isotherm adsorption experiments, except the incubation time kept at $1 \mathrm{~h}$. After incubation, the particles were washed with $2 \mathrm{~mL}$ water two times and $1 \mathrm{~mL}$ of 2.5 $\mathrm{mmol} / \mathrm{L}$ oxalic acid $a q$ two times, successively. After that, the particles was re-immersed in $0.2 \mathrm{M} \mathrm{Cu}(\mathrm{II})$ aq solution for $30 \mathrm{~min}$, followed by washing with pure water for two times. And the particles was used to absorb OTC again. The same cycle was repeated 7 times. As shown in Figure S6, the absorption efficiency of $\mathrm{Cu}$-mMIPs towards OTC still keeps above $91.4 \%$ after seven cycles. Notably, no color of $\mathrm{Cu}(\mathrm{II})$ is 
observed in the washing (water) step. As comparison, the eluent (oxalic acid aq) changes to blue. It indicates the complex can keep stable in water environment and the coordination is broken when treated with oxalic acid.

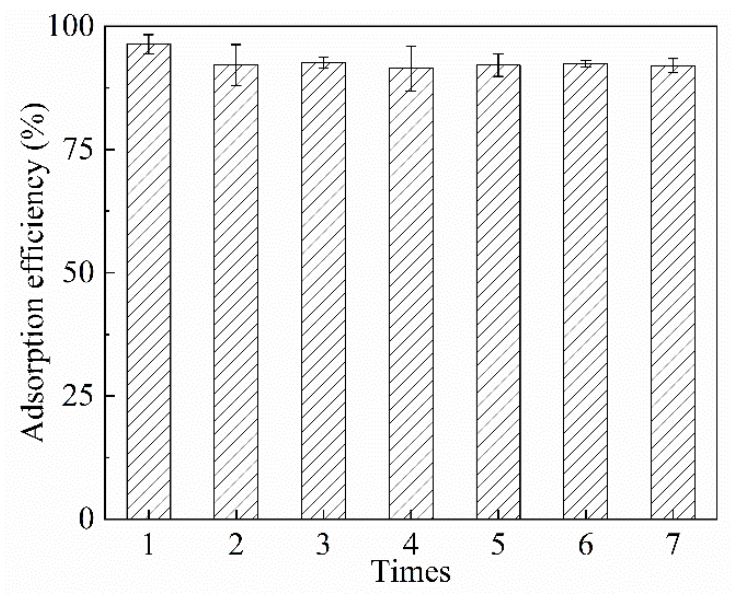

Figure S6. The reusability of $\mathrm{Cu}-\mathrm{mMIPs}$.

\subsection{The pH Suitability of Cu-mMIPs}

The $\mathrm{pH}$ value of the sample solution is always an extremely important factor affecting the adsorption efficiency, because it may be changing the charge type on the surface of the imprinting material, and lead to different adsorption effects of $\mathrm{Cu}$-mMIPs. As shown figure S8, the loading solution was conducted in $\mathrm{pH}$ ranging from 2.0 to 13.0. For $\mathrm{Cu}$-mMIPs, the adsorption efficiencies of OTC are greater than $80 \%$ from $\mathrm{pH}$ 5.0 to 11.0 , which indicates that $\mathrm{Cu}$-mMIPs can be applied in environment with large $\mathrm{pH}$ scope. It could be the coordination between $\mathrm{Cu}(\mathrm{II})$ and amino groups is stable in above $\mathrm{pH}$ values.

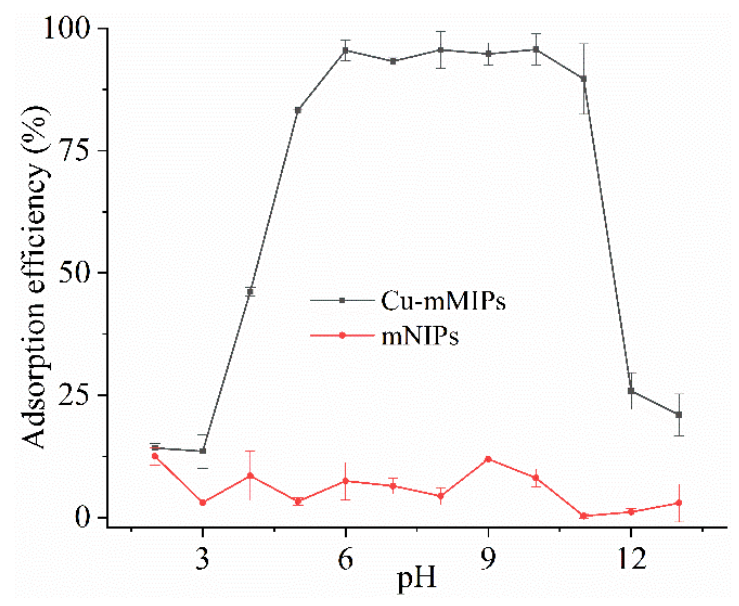

Figure S7. The adsorption efficiency of Cu-mMIPs andm mNIPs for OTC at different $\mathrm{pH}$.

\subsection{Analysis of OTC in Real Sample}

In this work, one HPLC-UV-VIS method was proposed to analyze OTC in different fractions before and after treated with $\mathrm{Cu}$-mMIPs. Firstly, one standard curve was established. The linear regression equations is $\mathrm{y}=1.114 \times 10^{4} \mathrm{x}-1.437 \times 10^{4}(\mathrm{R}=0.9991)$. The limit of detection is $20 \mathrm{ng} / \mathrm{mL}$. And the typical chromatograms are listed in Figure S8. As seen, the peak corresponding to OTC can be found in the eluent. 
Moreover, no other peaks appear, suggested almost all interferences originating from biological matrix were removed after treated with $\mathrm{Cu}$-mMIPs. It indicates the high feasibility of $\mathrm{Cu}$-mMIPs applied to analyze OTC in complex sample.

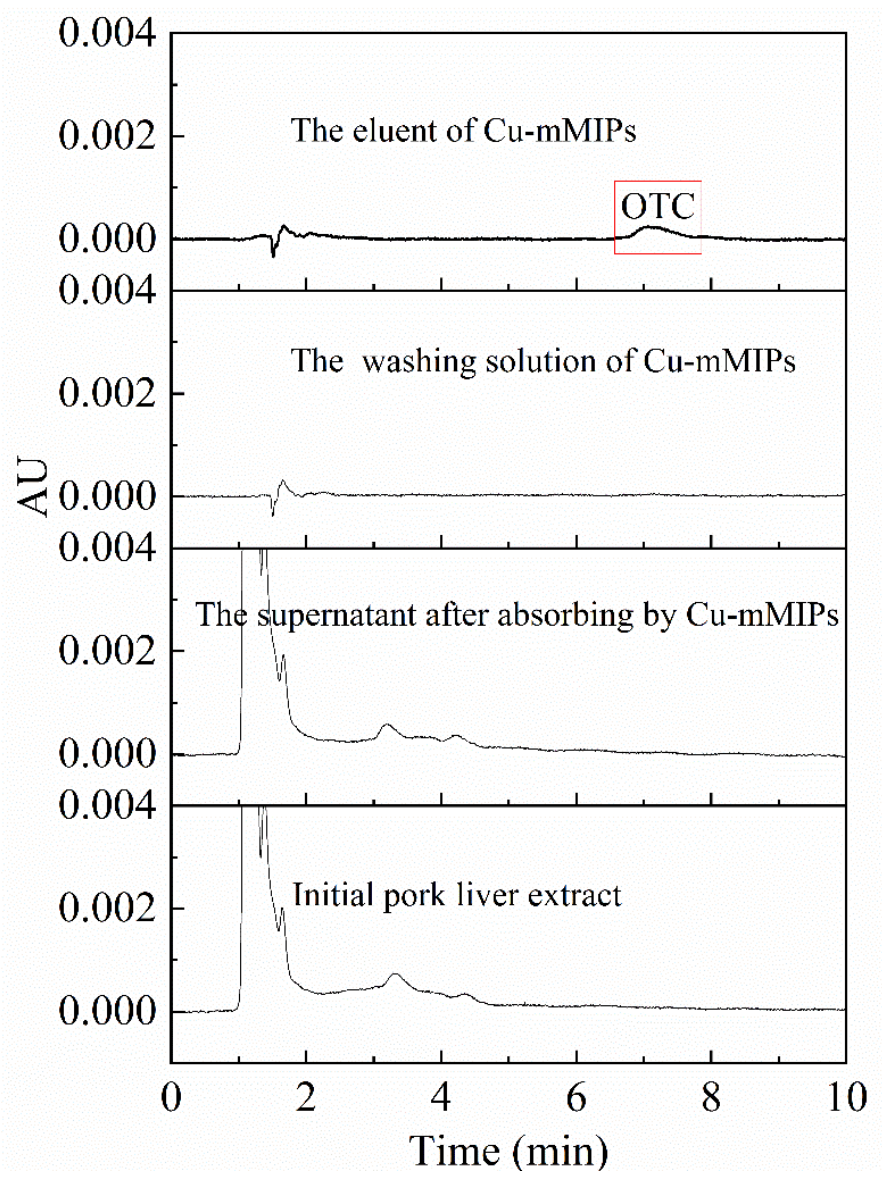

Figure S8. Typical chromatograms of different fractions before and after treated with $\mathrm{Cu}-\mathrm{mMIPs}$. 
Table S2. Analytical results of real samples at three spiked levels $(n=3)$.

\begin{tabular}{|c|c|c|c|c|c|}
\hline No. & Added $(\mu \mathrm{g} / \mathrm{kg})$ & Measured $(\mu \mathrm{g} / \mathrm{kg})$ & Recovery (\%) & Average recovery $(\%)$ & $\operatorname{RSD}(\%)$ \\
\hline 1 & 100.0 & 89.8 & 89.8 & 92.8 & 3.0 \\
\hline 2 & & 95.2 & 95.2 & & \\
\hline 3 & & 94.5 & 94.5 & & \\
\hline 4 & 300.0 & 284.8 & 94.9 & 91.0 & 4.5 \\
\hline 5 & & 260.5 & 86.8 & & \\
\hline 6 & & 275.7 & 91.9 & & \\
\hline 7 & 1000.0 & 954.3 & 95.4 & 94.2 & 2.0 \\
\hline 8 & & 916.9 & 91.7 & & \\
\hline 9 & & 936.8 & 93.7 & & \\
\hline
\end{tabular}

\section{References}

(1) Zhang, Y.; Xie, Y.; Zhang, C. G.; Wu, M. Y.; Feng, S. Preparation of porous magnetic molecularly imprinted polymers for fast and specifically extracting trace norfloxacin residue in pork liver. J. Sep. Sci. 2020, 43, 478-485.

(2) Wang, J.; Wei, J. Selective and simultaneous removal of dibenzothiophene and 4-methyldibenzothiophene using double-template molecularly imprinted polymers on the surface of magnetic mesoporous silica. J. Mater. Chem. A 2017, 5, 4651-4659.

\section{Author Contributions}

Y. Zhang and S. Feng conceived the research plan and designed experiments. Y. Zhang and Y. Xie performed the experiment. H. Shi and C. Zhang did HPLC analysis. Y. Zhang, Y. Xie and Z. Wu performed the data analyses and interpretation. All authors collectively discussed and contributed to the final version of the manuscript. S. Feng supervised all aspects of the project. 